\title{
Role of Local Policies in Facilitating Adaptation of Smallholder Farming to Climate Change in Uganda
}

\author{
Revocatus Twinomuhangi ${ }^{1,2^{*}} \quad$ Carolyn Natuhwera ${ }^{3} \quad$ Edidah L. Ampaire ${ }^{4,5}$ \\ 1.Department of Geography, Geo-Informatics and Climatic Sciences, Makerere University. P.O. Box 7062, \\ Kampala Uganda \\ 2.Makerere University Centre for Climate Change Research and Innovations, Makerere University, P.O. Box \\ 7062, Kampala Uganda \\ 3.Department of Environment Management, Makerere University, P.O. Box 7062, Kampala Uganda. \\ 4.International Development Research Centre (IDRC), Regional Office for Sub-Saharan Africa, \\ P.O Box 62084, Nairobi Kenya \\ 5.International Institute of Tropical Agriculture (IITA), 15 East Naguru Road \\ Upper Naguru, Kampala 7878, Uganda
}

\begin{abstract}
The research was funded by a USAID project entitled 'Enhancing Climate Resilience of Agricultural Livelihoods' that was implemented by the International Institute of Tropical Agriculture (IITA in partnership with Makerere University Centre for Climate Research and Innovation (MUCCRI) and the National Agriculture Research Organization (NARO). The CGIAR program on Climate Change, Agriculture and Food Security (CCAFS) provided additional support.
\end{abstract}

\section{Abstract}

Smallholder farming in Sub-Saharan Africa is highly vulnerable to the impacts of climate change and supportive local policies and plans are needed guide climate resilient farming systems. This study explores how local policies are enabling adaptation of smallholder farming to the impacts of climate change in Uganda. A mixed methods approach was used including review of policies and other literature, field assessments conducted Eastern and Central regions of Uganda. Data was collected from smallholder farmers, government officials and non-state actors at district, sub-county and village levels. Findings reveal that whereas Uganda has an elaborate national climate change policy framework that prioritizes the mainstreaming of climate change in policies and practices at all levels of government, development policies and plans at the local levels have not yet adequately incorporated climate change, and the adaptation practices adopted by smallholder farmers to address the negative impacts of climate change are more reactionary, and are not guided or influenced by local adaptation policies. Effective local adaptation policy and practice is constrained by non-inclusive policy formulation processes, institutional and human resource gaps, climate finance and unreliable climate information and advisory services. We suggest the strengthening local adaptive capacity through inclusive local adaptation policy formulation and implementation, improved climate information services and strong local institutional framework to support smallholder farmers build resilience to climate change.

Keywords: climate risks, vulnerability, local adaption policies, resilient agriculture, Uganda

DOI: $10.7176 / \mathrm{JEES} / 9-11-09$

Publication date: November $30^{\text {th }} 2019$

\section{Introduction}

Climate change has increasingly become a major challenge to agriculture, food security and rural livelihoods in Africa (CDKN 2014; IPCC 2015; Connolly-Boutin \& Barry 2016) and over the past decade, adaptation planning has becoming central in climate policy (Preston et al. 2015; Olazabal et al. 2019). The impacts of climate change fall hardest on smallholder farmers in developing countries because they have low ability to adapt and innovative policies and practices are still lacking to bolster local adaptive capacity (IIED 2013). Globally, about 1.5 billion people live in smallholder farming households, and in Africa smallholder famers manage about $80 \%$ of the farmland providing up to $80 \%$ of food need (FAO 2012; IFAD 2013). However, smallholder farming in this region is mainly rain-fed and highly vulnerable to climate risks (Lobell et al. 2011; IIED 2013).

Like other Sub-Saharan Africa countries, Uganda's agricultural community is highly vulnerable to climate change. Between 1900 and 2009, average annual temperature in Uganda increased by between $0.8-1.5^{\circ} \mathrm{C}$, and between 2000 and 2009 rainfall averaged about $8 \%$ lower than the period between 1920 and 1969. Climate change projections suggest a hotter country with temperatures likely to increase by between 1.5 and $3^{\circ} \mathrm{C}$ in +50 years (Ministry of Water and Environment 2015). The vulnerability is very high due to dependence on agriculture and natural resources and high poverty levels (USAID 2013; Government of Uganda 2014a; World Bank Group 2015).

The achievement of climate resilient agriculture requires better and coherent policies, and institutional support to implement the policies (FAO 2010; Cobb et al. 2015). For decades, the United Nations Framework Convention on Climate Change (UNFCCC) has invested substantial effort in guiding countries develop enabling policy environments. Many governments have formulated national policy frameworks such as National Adaptation 
Programmes of Action (NAPAs), national climate change policies, strategies and plans, and National Adaption Plans (NAPs) aimed at guiding and supporting climate change adaptation and mitigation practices. According to Morton (2007), local policies that incorporate adaptation action can play a significant role in building climate change resilience mainly because climate risks and vulnerabilities are area specific due to varying physical, socioeconomic, demographic and policy issues, and thus addressing them requires locally appropriated policies and practices. However, most Sub-Saharan Africa countries have not yet succeeded in translating the national climate change policies into local implementable adaptation policies and practices (Madzwamuse 2010; Ampaire et al. 2017).

The Paris Agreement on Climate Change recognizes the role of national and local climate change policies and emphasizes community driven adaptation actions (United Nations 2015). Local adaptations policies could be in the form of strategies or plans that define the interventions to reduce vulnerability to assessed or perceived climate risks and ways to building resilience (Olazabal et al. 2019). According to Pohlmann (2011), not only do locality and local actions play an important role in adaptation to climate change, but local governments possess tools and instruments, including legislative and executive control, for translating global and national climate change policies into local adaptation policy and interventions. In addition, local adaptation action does not only exist as top-down decisions, but these actions should provide lessons for national policy.

Some countries' local entities have formulated and implemented local adaptation policies and plans, but most of them are urban centred (Araos et al. 2016). Four cities on different continents are internationally recognized as early adaptors and successful in local adaptation policy and planning including Copenhagen (Denmark), Durban (South Africa), Quito (Ecuador) and Vancouver (Canada) as they have adaptation plans, and their adaptation actions and successes are well documented (Araos et al. 2016; Olazabal et al. 2019). In Uganda, Kampala city has formulated and is implementing a climate change strategy that aims at mainstreaming climate change in the city's services (KCCA 2016), but its success is not yet evaluated. Elsewhere in the developing world, Nepal is a good example of a country that has developed a Local Adaptation Plan of Action that guides integration of climate change adaptation into local development planning (Government of Nepal 2011). Piloting has been done in eight highly vulnerable districts of Nepal involving formulation of local adaptation plans whose implementation has enhanced community-based adaptation and resilient farming (Peniston 2013). Kenya is implementing a devolved climate finance framework that has enabled sub-national governments/counties to institutionalize a county climate change fund that is enhanced the local governments' climate finance readiness and enabling them invest in priority community adaptation actions (Development Initiatives, 2019). In Nepal and Pakistan, local government policies backed by incentives are effective in building the adaptive capacity of communities (ICIMOD 2012). For Pakistan, while local institutions were effective in enhancing the adaptive capacity of communities to water stress, a disconnect between sectoral and local policy and planning was hindering effective water resource management.

Local governance in Uganda is decentralized based on a district as a 'unit' responsible for local government planning, budgeting and regulation (Government of Uganda, 1997). Uganda's decentralization policy envisions good governance based on democratic participation and decision-making by communities in consistence with national laws and development objectives. Friis-Hansen et al. 2013; Hoppe et al. 2014; Okiror et al. 2017 posit that local governments are crucial in building climate resilience through formulation and implementation of local adaptation policies because the local governments are in more direct contact with the vulnerable communities. And, since adaptation interventions are largely implemented at community level, local governments are the institutions best suited to guide farmers adapt to climate change. The countries' local policies mainly seek to operationalize national policies but in a manner that addresses local challenges. There are a few examples local governments in Uganda that have, on their own/and or through donor support, been able to develop local environment and climate change policies. For example, with support from the French Development Agency, Kampala city developed a climate change strategy. On its own, Amuria district formulated an environmental ordinance that prohibits the cutting of endangered tree species (shea nuts and tamarind species) widely used for charcoal burning, and prioritizes the protection of wetlands and development of wetland management plans aimed at mitigating flood risks. However, Friis-Hansen \& Aben (2017) find that Uganda's disaster/emergency response policy and practice is still centralized, and not in alignment with the Uganda's decentralization policy and is thus a hindrance to local level disaster risk management efforts.

Despite the considerable progress on the climate change policy arena in Uganda, limited studies have explored how local policies are enabling climate change adaptation in agriculture in Uganda and Sub-Saharn Africa in general. This limits a deeper understanding of the why and how local climate change adaptation policies are formulated and the extent to which they are effectively implemented to build sustainable and resilient agricultural systems. The adaptation policy studies conducted in Sub-Saharan Africa have mainly focused on climate change mainstreaming (Coob et al. 2015; Ampaire et al. 2017) and on lessons learned and experiences from implementation of NAPAs (Friis-Hansen et al. 2013; Kissinger et al. 2013; Nyasimi et al. 2016). While some studies have could have documented local adaptation policy and practices, they largely focus on urban systems (Cobb et al. 2015, Araos et al. 2016; Olazabal et al. 2019) and do not address rural based climate resilient 
agricultural systems knowledge needs. This was conducted to provide a deeper understanding of the role local policies play in facilitating adaptation of smallholder farming to the impacts of climate change in Uganda.

\section{Methodology}

The study was conducted in Central and Eastern Uganda, with Luwero and Mbale districts as the study sites respectively (see Figure 1). The study adopted a mixed methods approach involving a desk review of policies and plans and other related literature, a formal survey, male and female segregated focused group discussions, and key informant interviews.

\subsection{Desk review of policy documents and related literature}

National, sectoral and local development and climate change policies and plans, ordinances and byelaws, and climate change action plans relevant to the two study districts were reviewed, exploring how they characterized and provided for climate change adaptation. Policy reviews provided information on policy formulation provisions, linkages between local and national policy, and the stipulated roles of different stakeholders. Literature on climate change policy and practice from outside Uganda was also reviewed. In all, the review of literature provided indepth understanding of the role of local policies in climate adaptation processes and lessons learnt.

\subsection{Household survey}

A household level survey was conducted in the Central and Eastern regions of Uganda with Luwero and Mbale districts as the study sites respectively (see Figure 1). The two regions were selected because of their contrasting climate change exposures and vulnerabilities, which were largely associated with variation in altitude, rainfall and temperature, and the policy interventions in place. Mbale district, which experiences rampant landslides and floods, had a climate change policy, the Integrated Territorial Climate Change Plan (ITCP), but Luwero district located in a drought prone and water stressed area did not have a specific climate change policy or plan. The two regions have a bimodal rainfall distribution, usually received during two seasons, the March to May and September to December season and the March to May and September to December season. Luwero district is a low altitude region, 1,219 - 1,524 meters above sea level (masl). The terrain is generally flat consisting of elevated and dissected plateau with flat-topped hills and intervening valleys (Luwero District Local Government 2010). The district has been experiencing persistent droughts since the 1990s. Economically, about $80 \%$ of the households in Luwero are engaged in agriculture with land holdings of about 2 ha, of which the cropped land is about $36 \%$ of the landholdings (Luwero District Local Government 2010). About 22\% of the population in the Luwero sub-region is below the poverty line (UBOS 2017).

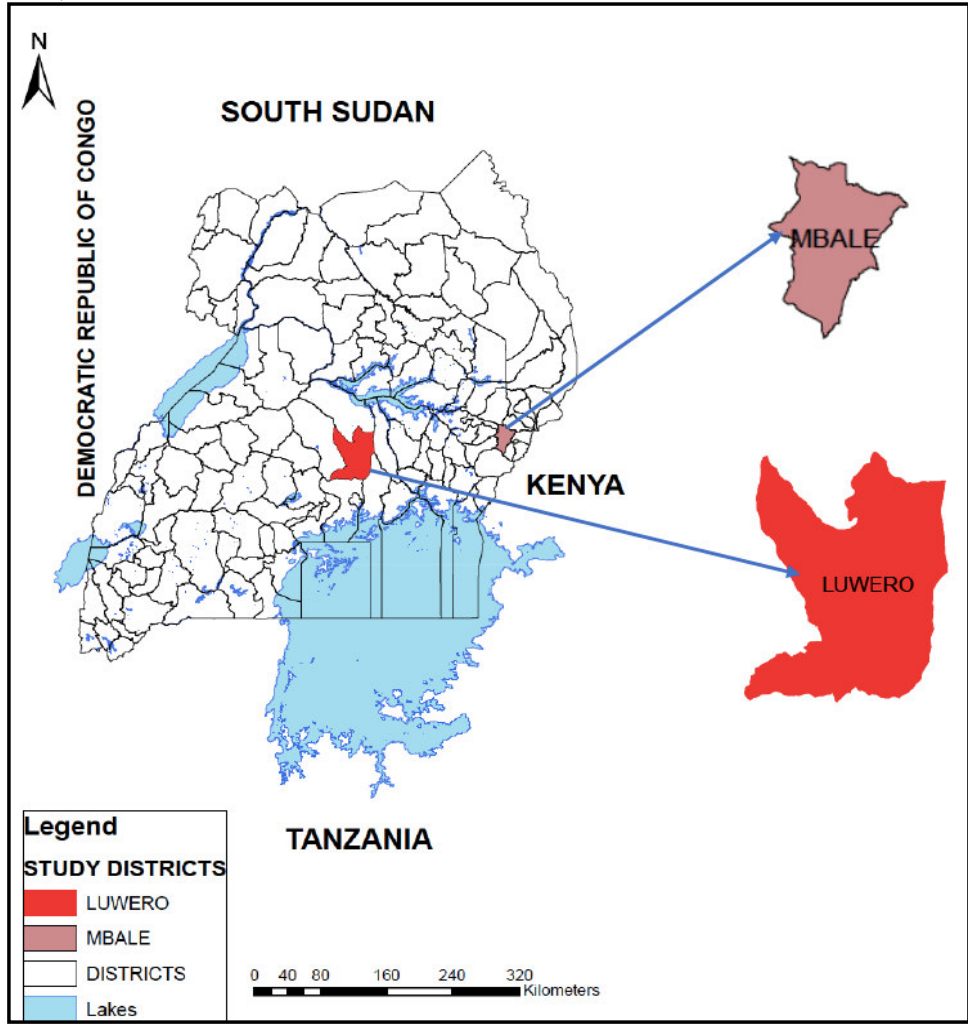

Figure 1. Location of study area in Uganda 
Mbale district is located is located in the Mt. Elgon region and its landscape has distinct topographical zones with their corresponding altitudes: lowland $<1,500$ masl, upland/highland 1,500 $-1,800$ masl and mountainous $>$ 1,800 masl, but the biggest proportion of the district is mountainous (Mbale District Local Government 2010; Government of Uganda 2013). The area often experiences variations in rainfall patterns, intensive rainfall, as well as floods and landslides (UNDP 2013). About $72 \%$ of the population depends on subsistence agriculture and although the average landholdings in the district are slightly less than 2 ha, about $26 \%$ of the households have landholdings less 0.4 ha (Mbale District Local Government, 2010). About 41\% of the population in the Mt. Elgon region, where Mable district is located, is below the poverty line (UBOS 2017).

A total of 96 small-scale farming households were randomly sampled from eight villages that were randomly drawn from four sub-counties: Kamila and Zirobwe sub-counties in Luwero district; and Bufumbo and Namanyonyi sub-counties in Mbale district. From each household selected, the household head was interviewed, making a total of 96 respondents. Where the household head was absent, his/her adult representative was interviewed. The household respondents provided information on perceived effects of climate change, adaptation practices and how policy influences uptake of adaptation practices.

\subsection{Focused Group Discussions}

Sixteen gender-segregated Focus Group Discussions (FGDs) were conducted with farmers in eight villages drawn from four sub-counties whose selection is already described in section 2.2. A total of 156 farmers (80 females and 76 male) participated in the FGDs. The discussions provided information on policy formulation and implementation processes, and farmers' perceived drivers of uptake of adaptation practices.

\subsection{Key informant interviews}

Semi-structured interviews were conducted with 28 key informants consisting of district and sub-county technical staff, political leaders, community leaders, and Non-Governmental Organizations (NGO) and Community Based Organizations (CBO) staff operating in the two districts. The key informants provided their experiences on policy formulation and implementation process, and their perceptions on how policy could have influenced uptake of adaptation options.

\subsection{Data analysis}

Quantitative data from the household survey were analyzed in the Statistical Package for the Social Sciences (SPSS) Version 21, and summary descriptive statistics generated. For qualitative data obtained from FGDs and key informant interviews, a framework analysis approach (Spencer et al. 2003) was used in the analysis, developed in the context of applied policy research (Lacey \& Luff 2001). Qualitative data were transcribed and typed out in MS word and entered into ATLAS.Ti qualitative data analysis software and thematically grouped to show showing interrelation. Presentation of results was then done thematically.

\section{Results}

3.1 Local policy instruments at district and sub-county levels

Local policies in this study are defined to include plans, strategies, rules and guidelines formulated by a local government authority (district, urban or sub-county council) for purposes providing general direction towards the achievment of medium to long-term local development (and other) goals and or/decision making guided by the national vision, policy or strategic direction. Although local policies and plans are supposed to originate from the grassroots level and inform sector policies and plans, they are also supposed to translate national/sector policies and strategic development strategies into priorities to be adapted by the local governments (Government of Uganda 2014b). For climate change adaptation, the policies considered in the study were those that define objectives and activities geared at increasing the resilience of communities to the impacts of climate change. District and subcounty local governments are interconnected in planning and implementation because the district is the higher local government while the sub-county (and urban authority) is the lower local government. However, both the district and sub-county local governments are in a way autonomous as each develops and implements its own policies, plans and strategies. In accordance with Uganda's decentralization law, District Local governments are obliged to prepare plans that incorporate the plans of lower local governments in their areas of jurisdiction (Government of Uganda 1997). In this paper, we categorize local policies into "formal policies" and "informal policies". The formal policies we identified to include written policies formulated, which according to the local government planning guidelines include: local development plans, ordinances, byelaws, and stand-alone climate change plans. Informal policies, on the other hand, are undocumented customary rules and norms instituted by communities to address issues of concern.

\subsubsection{Local Development Plans}

Local development plans are the main tools for the implementation of decentralized governance in Uganda and define the development programs and services to be implemented by government and non-government actors in 
local governments (Government of Uganda 2014). Both Luwero and Mbale districts had five-year District Development Plans (DDPs) for the period 2010/2011 to 2014/2015. The DDPs laid down planned activities and the associated implementation budgets. The districts also had local sectoral plans that were aligned to the DDPs and sector plans at the national level.

Sub-counties had five-year sub-county development plans and annual action plans. Although the two study districts are highly vulnerable to the impacts of climate change (especially rising/extreme temperatures, droughts, variations in rainfall seasons, floods, landslides etc.) that affect agricultural production, a review of the DDPs for the two district revealed that were largely 'climate change blind' i.e. The DDPs were not mentioning the current and likely future climate change risks faced by the districts and how they affect agriculture, water availability, and other sectors that support agricultural production, nor did they mention the priority climate resilient agricultural interventions. The Mbale DDP recognizes that the district is highly exposed to landslide hazards and had a policy provision on climate change i.e. strengthening climate change policy and institutions the interventions but had no budget line to finance implementation of this policy priority. At the sub-county level, farming communities mentioned the effects climate of variability as a major hindrance to farming, but the sub-county fiver year development plans did not incorporate of climate change related interventions for addressing climate variability and climate change.

The key informants at district level described some of the agriculture and natural resource management policy provisions in the DDPs including tree planting, agroforestry, improved planting material, pests and diseases control as 'climate change related', and saw no need of incorporating climate specific interventions in the DDPs. Thus, with DDPs not incorporating climate change and district officials seeing no need for mainstreaming climate change into development plans, the smallholder farming needs cannot be adequately addressed in local policy.

3.1.2 Ordinances and byelaws

The two districts had developed what may be termed as 'climate change related' ordinances e.g. the Luwero District production and environment management ordinance of 2006; the Luwero District Sustainable Charcoal Production and Licensing Ordinance of 2008; and the Mbale District environment and natural resources management ordinance of 2012. These ordinances include provisions that could support adaptation to climate change e.g. sustainable land management, tree planting and agro-forestry, sustainable charcoal production and energy security, water and wetland resources management and sustainable agriculture. Our analysis finds that the ordinances do mention climate variability/change or adaptation, but are climate relevant and could provide a basis for adaptation planning and practice, but the implementation/enforcement of the ordinances was still a big challenge. In Mbale district the challenge is largely external to the district because the ordinances were still pending the approval by Solicitor General (at national level) more than a decade after the District Council approved them. The Mbale District Council had not yet approved the Mbale District Environment and Natural Resources Management Ordinance of 2012. As a result, charcoal production in Luwero continues unabated, and deforestation in both districts are still a big challenge. In all, local adaptation policy formulation and implementation is lengthy, bureaucratic and constrained by politicization of environmental management and poor funding of the district and environment management services. Even then, effective implementation of these ordinances can only provide a basis for community adaptation but may not build community resilience because they are framed to address current challenges and do not consider future climate risks.

At the lower local government level, the two sampled sub-counties in Mbale (Bufumbo and Namanyonyi) had developed byelaws to control the spread of the banana bacterial wilt (BBW) disease, which the farmers erroneously perceived to be caused by climate change. The sub-counties put in place strong tasks force that enforced implementation the BBW, and coupled with community mobilization and vigilance the spread of the disease was largely contained. Although BBW is not directly a climate change challenge, the disease destroys the banana crop and erodes food security and household incomes, and is thus an indirect driver of vulnerability to climate change. Interestingly, although Luwero was also facing BBW challenge, the sub-counties in the district had no byelaw to control its spread. The Mbale case provides lesson learning for Luwero and other districts of Uganda that effective law enforcement and community engagement is more effective to policy implementation, strengthening community productivity and environment management which provide a firm foundation for adaptation policy and practice.

3.1.3 Stand-alone climate change policies

Mbale district had a stand-alone climate change plan, The Integrated Territorial Climate Change Plan (ITCP) 2014-2029 for Mbale region of Uganda. The plan, developed in 2013 with support from UNDP under the Territorial Approach to Climate Change (TACC) project aims to 'assist the Mbale region to achieve low carbon and climate resilient development' (Government of Uganda 2013). The adaptation and investment options lain down in the ITCP include: resilient coffee production; sustainable use of wetlands; sustainable intensification of crop and livestock production systems; agroforestry, and sustainable irrigation schemes for smallholder farmers. The ITCP is not for Mbale district alone but is a regional plan for three districts (Mbale, Bududa and Manafwa) and it was not developed through the legally established local policy formulation/planning process, and discussed 
revealed that the plan was not very popular among district technical staff and political leaders. Although all the key informants were aware of the ITCP, it was revealed that implementation of the plan is constrained by financial and institutional challenges.

Only $38 \%$ of farmers interviewed were aware of the adaptation options in the ITCP but they had not started implementing them because of skills and financial constraints. A general feeling is that the interventions in the ITCP are very expensive to implement and geared at attracting donor funding. So far, the district authorities had not yet succeeded in mobilizing financial resources to implement the plan. Moreover, Mbale District had not yet put in place an institutional structure to roll out implementation the plan. Thus, the implementation of the plan had not yet begun and smallholder farmers had not adopted its interventions.

Luwero district did not have a standalone climate change action plan/strategy and had not put in place an institutional structure to implement climate change activities. This implies that local adaptation policy was not guiding smallholder farmers' response to the effects of climate change.

3.1.4 Informal policies

Some communities had formulated byelaws, rules and norms to address specific challenges related to environment and natural resources, agricultural production and food security. Examples included rules compelling each household to plant trees in both districts and those for controlling bush burning in Luwero district. Luwero communities had informal regulations on maintaining water sources and regulating charcoal burning. In Mbale, rules on contour farming and digging trenches to reduce run-off and soil erosion featured prominently because the area is mountainous and fragile.

Discussions revealed that informal policies were more known to the farmers and relatively more binding than formal policies are. It was also revealed that rules on environment and natural resource management were more difficult to enforce as compared to those related to production/livelihood improvement because communities were not deriving immediate socio-economic benefits from the former.

\subsection{Extent to which local policies influence adaptation to climate change}

Farmers in the study area revealed that they had adopted a range of adaptation practices (summarised in Figure 2), and key among them in Luwero district are: planting trees, crop diversification, rainwater harvesting and expanding farmlands. In Mbale district, conservation agriculture, intercropping, fertilizers/manure use, post-harvest technologies, non-farm activities and small-scale irrigation were the main adaptation practices adopted

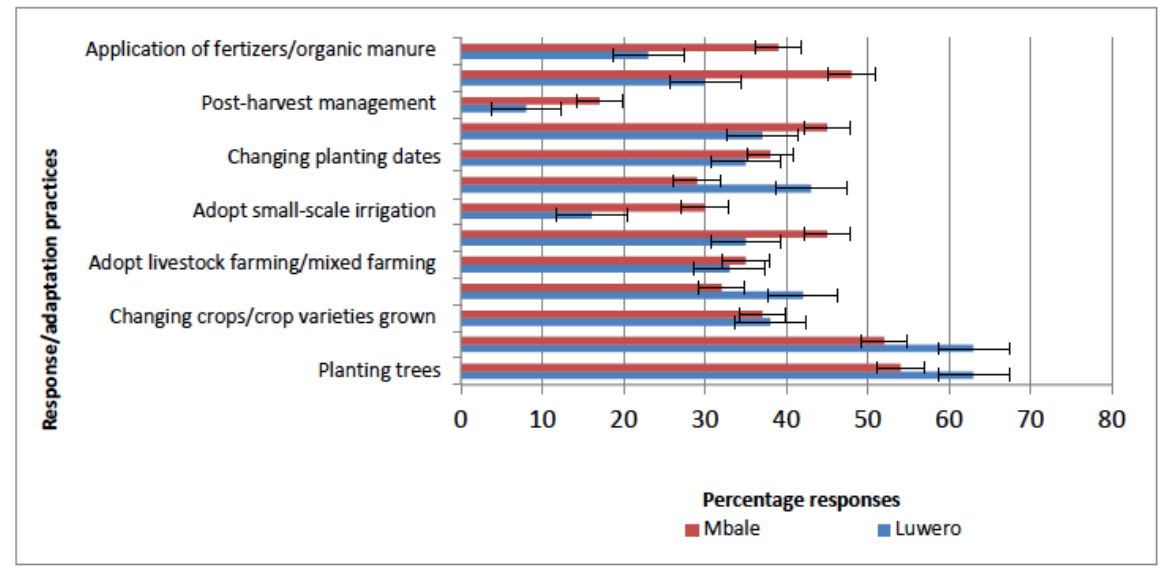

Figure 2. Adaptation practices adopted by farming households in Luwero and Mbale Districts

The findings from FGDs (Figure 3) revealed that the main drivers of uptake of adaptation practices by smallholder farmers in the two districts were not influenced by policy. The main drivers of uptake were: need to ensure household food and income security and having experienced poor harvest in previous seasons, in which for Mbale it was more significant for women compared to men. In addition, farmers in Mbale had received planting materials and this was significant for men compared to women.

It is noteworthy that policies, whether formal or informal, had the least influence on the uptake of adaptation practices by smallholder farmers (Figure 3) in the two districts. Indeed, $82 \%$ of the farmers in Luwero and 63\% in Mbale that participated in the FGDs were not aware of any policies being promoted by their local governments to promote adaptation. Asked about why they did not consider policies as enablers of adaptation, key informants revealed that community members were not aware of the polices as they are not effectively involved in their formulation, and few if any information campaigns were conducted to raise public awareness of the policies. Additionally, ineffective extension services limited implementation of adaptation policies and practices at community, household and farm level, and discussions revealed that the main constraint was insufficient funding 
to local governments. The sampled sub-counties did not have adequate extension staff to advise farmers on climate smart agricultural practice, and the communities visited revealed that they were not holding regular community planning meetings where awareness raising on adaptation policies and practices could have been conducted.

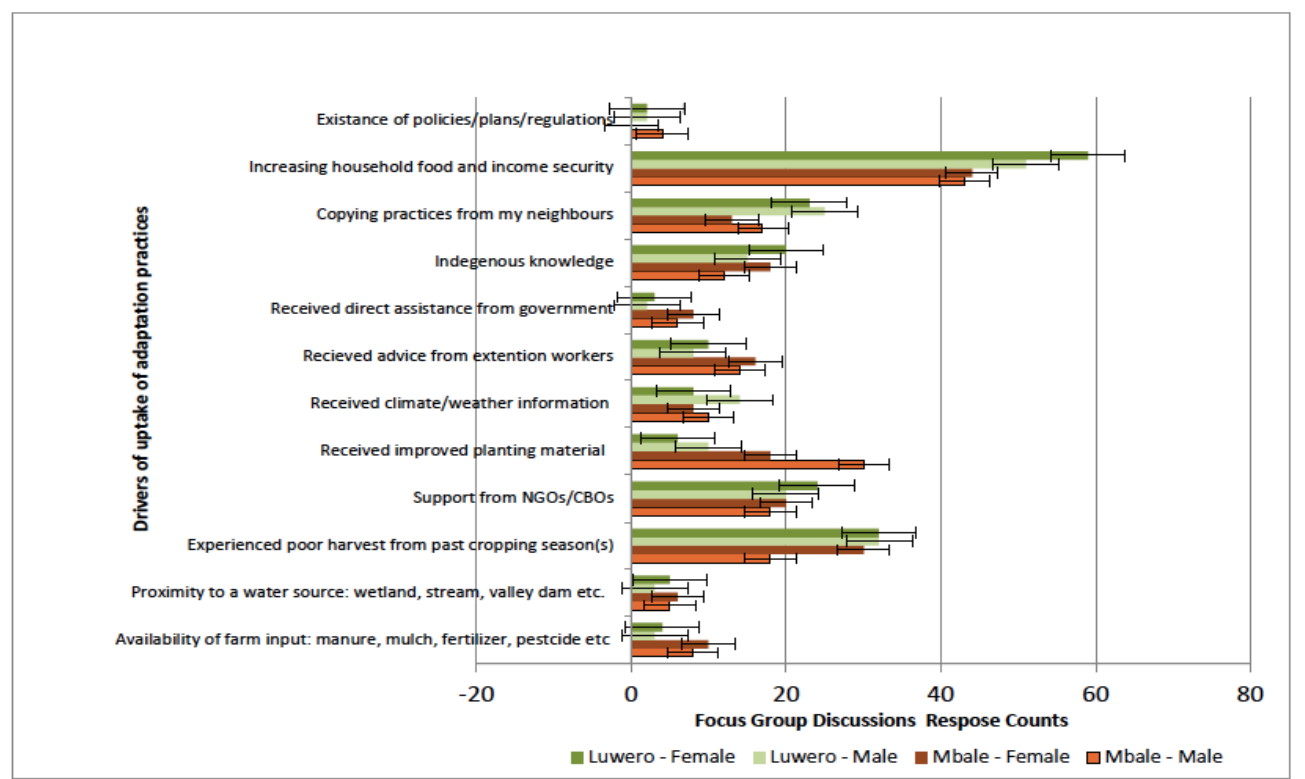

Figure 3. Drives of uptake of adaptation practices by smallholder farmers in Luwero and Mbale districts * Negative standard errors indicate that the driver was not reported in the districts.

\subsection{Policy challenges for enabling climate resilient smallholder farming}

Local policy development can enable community-based adaptation and increase the resilience of smallholder farming to a changing climate. However, the development of adaptation policies, plans, strategies and mainstreaming climate change adaptation into local development plans is just one route, and other enablers are crucial to implementing the policies and delivering resilient farming practices. Discussions held in the study revealed several policy challenges that constrain smallholder farmers from adapting to climate change.

3.3.1 Non-inclusive policy formulation and implementation processes

Whereas Uganda's local government planning guidelines provides for a participatory process (Government of Uganda 2014b), discussions with key informants revealed that communities are not effectively participating in policy formulation which hinders their implementation. For example, sub-county councilors (representatives) attend district planning sessions, but village and parish levels were not invited for planning meetings.

The planning process should be participatory in line with the local government planning guidelines, but we do not participate in planning meetings.... I think we implement only $20 \%$ of what is provided by the guidelines...(KII - Luwero District)

Discussions also revealed that ordinances and byelaws had been developed with a few consultations with subcounty technical staff. In Mbale District, BBW byelaw had been formulated and passed by the sub-county councils without adequate consultations, and only disseminated to the communities for implementation. The ITCP for Mbale region was formulated in a participatory manner but the consultations were outside the district policy process, implying it was formulated outside the local government planning process and lacked ownership by the local authorities.

3.3.2 Inadequate institutional mechanism to enable policy implementation

Strong institutional structures are necessary to support implementation of adaptation interventions at all levels, but the districts lacked climate change institutional structures or committees. The environment management committees that would have supported adaptation were non-existent at community levels, only existing at subcounty and district levels but also largely non-functional. The only committees found to be functional at community level were water resource user committees in Luwero and the BBW control task forces in Mbale. At the time of the study, another challenge was that lower local council (LC1) leaders lacked legitimacy to effect law enforcement because their term of office (five years) had expired but they were illegally holding office for over 20 years because the government had not organized local council elections. Group discussions also revealed that lack of functional institutional structures was responsible for poor supervision and monitoring policy implementation.

3.3.3 Financing and budgeting

Climate finance is crucial to enhancing local adaptive capacity but Uganda faces climate finance constraints. 
Between 2008 -2012 the Government of Uganda had spent approximately only one percent of its annual budget on climate change related activities (Tumushabe et al. 2013). Uganda's local governments are financed through central government grants, local revenue, borrowing and donor funding (World Bank 2012). For the 2010/11 2014/2015 medium term expenditure, central government grants accounted for more than $90 \%$ of district financing. However, most of the funding was in the form of conditional grants without budgets lines for climate change, and local revenue was too small often less than $3 \%$ of the districts' budgets and could not to finance any meaningful climate change adaptation interventions.

The agriculture and natural resources sectors have very small budgets, and yet they handle most of adaptation issues affecting smallholder famers. In the financial year 2014/2015, agriculture and environment sectors were allocated $3.1 \%$ and $3 \%$ respectively in the national budget. In the district budgets, Luwero allocated agriculture and environment $2.1 \%$ and $0.5 \%$ respectively, while Mbale allocated agriculture and environment $6.7 \%$ and $0.3 \%$ respectively. Both districts had no budget lines for climate change. Discussions with district key informants confirmed that a funding gap constrains planning and implementation of environment and climate change adaptation activities the two districts.

Our analysis finds that the conditional nature of central government funding to local governments, the lack of climate change budget lines in national and district budgets, coupled with low local revenue collection constrains the ability of local governments to address climate risks and foster climate resilient agriculture. But, whereas nongovernment sources of climate change funding exist, key informants revealed that districts could not access donor funding because they lacked technical capacity to develop and implement climate change projects.

3.3.4 Human resources gaps

The two districts faced human resource gaps that constrained them from promoting climate resilient agriculture in communities. Less than 50\% of the staff positions in the Districts' Agriculture/Production and Natural Resources Departments were filled. The agricultural extension staffing levels were very low at only $35 \%$ in Luwero and $22 \%$ in Mbale and still the extension staff had not undergone any climate change training and lacked capacity advise farmers on climate smart agriculture practices. The farmers interviewed confirmed that they do not easily access agricultural extension and advisory services. The two Districts did not have designated climate change officers, and District Natural Resource Officers were acting as climate change focal points as additional responsibility but their job description had not been reviewed to include climate change, and so they were not giving it much attention. The officers had not received any climate change training to enable them foster climate resilient farming practices. 3.3.5 Climate information services

Smallholder farming in Luwero and Mbale districts practice rainfed agriculture but all the farmers interviewed revealed that they were not accessing accurate, regular and reliable weather and climate information to enable them plan their farming activities and adapt to climate risks. Where weather forecast information is provided, more than $90 \%$ of the farmers interviewed disclosed that they do not adequately understand the messages relayed. The districts lacked adequate coverage of modern weather monitoring stations and trained staff. Each of the two districts had only one weather station that was operational i.e. Bukalasa in Luwero, and Buginyanya in Mbale. Given that climatic conditions can vary even over a small area, one weather station in a district is not an adequate coverage to inform adaptation climate policy and practice. The key informants, including district technical staff, also revealed that the two districts' DDPs were developed without consideration of climatic conditions because climate information was not available.

\section{Discussion}

The study aimed at deepening our understanding of how local policies enable adaptation of smallholder farming to the impacts of climate change. Our study found that both formal and informal policies existed, formulated by local governments in line with Uganda's decentralized legal framework with the main formal local policies being local development plans i.e. the five-year DDPs at the higher local government level (district) and sub-county development plans at lower local governments. The local development plans had not incorporated climate change adaptation but the country's national climate change policy framework recognized emphasizes mainstreaming of climate change into national, sectoral and local development policies and plans (Government of Uganda, 2015a, $2015 b)$. Thus, the country's adaptation priorities and actions, that include climate resilient agriculture, had not yet been adequately incorporated in local development policy and practice.

Afrialliance (2019) finds that while most African countries have put in place national climate change adaptation policies, it still remains difficult to translate national policies to local adaptation policies and actions (FAO (2017). We find that smallholder farmers' adaptation practices are largely reactionary and not planned under guidance of local policy and planning. This agrees with Hisali et al. (2011); Luque (2013) who observe existence of inconsistencies between national and local adaptation policy. Bashaasha et al. 2013) posit that national climate change adaptation policies are not enabling local agricultural adaptation policy and practice and tend to be externally driven to fulfill Uganda's international climate change obligations and reporting to the UNFCCC. Wright et al. 2014; Okiror et al. (2017) argue that transformational adaptation for development capable of bringing 
about socio-economic benefits for the people has to be embedded in good local governance but more often local governments in Uganda do not promote good environmental and climate change governance due technical and financial capacity constraints.

Although local governments had formulated ordinances and byelaws that could fill the adaptation policy gap, the process of formulating them was very lengthy and bureaucratic. Some of the ordinances formulated by the two districts had for close to two decades not been approved at the national level by the Solicitor General and could not be implemented. Other studies observe that formulation and enforcement of byelaws and ordinances, more especially in the environment and production sectors, are not prioritized in Uganda (Mugumya 2013). Most of the soil and water conservation byelaws put in place in the 1960's and 1970s were not being enforced (Government of Uganda 2013) and the culture of non-enforcement of policies and regulations is slowly getting entrenched in the country. Political interference and conflicts between technocrats and politicians in enforcing environmental regulations especially on protection of forests and wetland remains a big challenge (Bashaasha et al. 2013; Ampaire et al. 2017).

On climate change specific policies, we found that Mbale district had a climate change plan, the ITCP but Luwero district did not have one. Interestingly, while various studies including Madzwamuse (2010); Bauer et al. (2012) have argued that local public policy is necessary for guiding and supporting community adaptation practices, we did not find a significant difference in the adoption of climate resilient agricultural practices among smallholder farmers in Mbale district that had a climate change plan and Luwero district that did not have one. Indeed, the majority of smallholder farmers interviewed in both districts, i.e. $82 \%$ in Luwero and $63 \%$ in Mbale, revealed that policies were not the main drivers to their uptake of adaptation practices. In Mbale most of the farmers interviewed in Mbale district were not even aware of this plan and so it was not guiding them in climate smart farming. Winthrop et al. (2018) agree that there is low awareness of adaptation policy in Uganda caused by inadequate participation in policy formulation. In addition, the role of communities in shaping policy formulation and effective implementation is not well appreciated (Ampeire et al. 2015).

Lack of funding was identified as a major constraint to implementation of the ITCP but key informants revealed that the plan lacks local ownership by the district authorities and mainly because the plan was developed outside the local government policy and planning processes/structures. Consequently, the plan had not secured the much-needed buy-in from district authorities to drive its financing and implementation. Okiror et al. (2017) are in agreement that funding constraints implementation of the ITCP but also note that while the formulation of the ITCP was largely participatory, parallel structures to the local governments were created mainly to legitimize the process which cannot be equated to real devolution of decision making. As a result, the ITCP was not popular with the local government staff. Elsewhere in Kampala city where the city's climate change strategy was developed in highly participatory manner and within the city's policy and planning structures, its implementation has largely been largely successful and the city has received support from the EU, World Bank, and the African Development Agency (AFD) to roll out the climate action plan.

Various policy challenges are constraining adaptation of smallholder farming to the impact of climate change including, non-inclusive policy formulation processes, inadequate local adaptation institutional frameworks and human resource gaps, climate finance, and gaps in climate information services provisioning. Uganda's local government planning guidelines emphasize inclusive and participatory planning processes (Government of Uganda 2014b) and some studies also recommend deliberate involvement of local communities and farmers in adaptation policy and planning (Satterthwaite 2011, Carmin et al. 2012). However, our findings affirm the findings of World Bank (2012); Banana et al. (2014); Tenywa et al. (2017) that local planning and policy formulation processes are deficient in inclusive planning as the agenda is set at the top and the policies and plans do not capture community needs and challenges, including those related to adaptation (Liwenga et al. 2014; Cochrane et al. 2017; Okiror et al. 2018). The national adaptation policies and programmes, like the NAPA (Government of Uganda 2007), emergence response policy and local adaptation plans (such as the ITCP) had been either formulated and/or were being implemented outside the local governance structures (Bashasha et al. 2013; Okiror et al. 2017) and yet local governments are in more direct contact with communities and farmers. Elsewhere, for areas where adaptation policy and planning has been inclusive and participatory, adaptation plans have been locally owned and successfully implemented resulting in enhanced adaptive capacity like in the cities of Quito in Equador and Durbun in South Africa (Carmin et al. 2012), and even in Kampala city of Uganda.

The absence of strong institutional structures to coordinate and guide climate change response makes local governments least prepared to mainstream climate change in local development plans, build local adaptive capacity, and guide famers to adopt climate smart agricultural practices. In particular, the existing human resource gaps, more especially in agricultural extension and advisory service is a major challenge for advancing adaptation in smallholder farming. Where production and agricultural extension workers exist, they often lack knowledge and skills in climate smart farming and cannot therefore advise farmers to adjust their farming practices to cope with a changing climate. Liwenga et al. (2014) observes that gaps in extension services limit the uptake of adaptation practices by smallholder farmers. Limited funding was also found to be major constraints to local adaptation policy 
and practice. Uganda government's budget and expenditure on environment and climate change related activities has been minimal and local governments do not have a climate change budget line. Studies including Tumushabe et al. (2010); Ampaire et al. (2017) contend that small budget and human resource gaps constraints implementation of environment management and climate change interventions. World Bank (2012) observes that communities in Uganda do not participate in planning due to lack of funds to convene meetings and Ampaire et al. (2017) notes that LGs fail to access donors funding because their technical staff fail to clearly articulate the climate change issues.

Whereas awareness of climate variability and access to climate information are important for guiding adaptation policy, planning and decision making (Jones et al. 2014; Mulinde et al. 2019), including uptake of climate smart agricultural practices, but we find the contrary in this study. Smallholder farming in the study area is mainly rainfed and farmers had adopted various coping practices that are not informed by reliable information on climate variability and climate risks. Mubiru et al. (2010) agrees that the climate information disseminated is often inconsistent and unreliable, and sometimes the opposite of what is predicted tends to occur (Tenywa et al. 2017). Indeed, all the farmers interviewed revealed that they were not accessing regular and reliable climate information and warning alerts to enable them prepare to mitigate climate risks. While some studies emphasize that climate information gives planners information for climate proofing development policies and plans (Jones et al. 2015; World Bank Group, 2015; Kajumba et al. 2016), local government planning in the two districts was not guided by climate information. Afrialliance (2019) agrees that implementation of climate resilient actions remains difficult because climate information is not available at local level where it is needed most to guide local adaptation policy and action.

\section{Conclusions}

The essence of this paper was to provide an understanding of how local policies facilitate adaptation among smallholder farmers in Uganda. This study concludes that while Uganda has a good national climate change adaptation policy framework, national adaptation policy has not yet translated into local adaptation policies and practices to enable climate resilient smallholder farming. And, where specific local level climate change plans have been formulated, like for Mbale district, their implementation is still constrained by lack of local ownership, and as well as technical and financial constraints. Although smallholder farmers had adopted varying coping responses to the impacts of climate change, we conclude that the adoption of these adaptation responses was not enabled by existence of local policies or plans and thus, adaptation of smallholder farming to climate change in Uganda is more reactionary and is not planned and is not likely to build long-term resilience. The adaption was also not informed by knowledge of climate variability and access to climate information and advisory service.

In view of the study findings, we recommend strengthening the local adaptive capacity through capacitated local governments to develop and implement, in an inclusive and participatory manner, innovative and coherent adaptation policies and plans informed by climate variability. Mainstreaming climate change in local development plans and budgets has to be prioritized because DDPs are the main development tools in Uganda's local governments and if climate change adaptation does not feature in these plans, then local development will continue to be 'climate change blind'. Addressing institutional, human resource and climate finance gaps, and strengthening climate information services remain important vehicles to strengthening local adaptation policies, planning and practices. Above all, detailed studies are needed to determine local vulnerabilities, capacity needs, as well as the adaptation and transformational options that can inform local adaptation policy and practice for enhanced agricultural resilience to the impacts of climate change.

\section{References}

Afrialliance. (2019), Scientific Knowledge and innovation advice for water and climate in Africa. Afrialliance Policy brief \#4.

Ampaire, E.L., Okalany, E. \& Providence, H. (2015), Governance and local institutional arrangements for climate change adaptation in Uganda: bridging public policy implementation gaps.

Ampaire, E.L., Jassogne, L., Providence, H., Acosta, M., Twyman, J., Winowiecki L. \& van Asten, P. (2017), Institutional challenges to climate change adaptation: A case study on policy action gaps in Uganda. Environmental Science and Policy 75: 81-90.

Araos, M., Berrang-Ford, L., Ford, J.D., Austin, S.E., Biesbroek, R. \& Lesnikowski, A. (2016), Climate change adaptation planning in large cities: A systematic global assessment. Environ Sci Policy Vol.66, pp 375-382.

Banana, A.Y., Byakagaba, P., Russell, A., Waiswa, D. \& Bomuhangi, A. (2014), A review of Uganda's national policies relevant to climate change adaptation and mitigation: Insights from Mount Elgon. CIFOR Working Paper No. 157. Center for International Forestry Research (CIFOR), Bogor, Indonesia.

Bashaasha, B., Thomas, T.S., Waithaka, M. \& Kyotalimye, M. (2013), Uganda. Book Chapter In: Waithaka. M., Nelson, C.G., Thomas, T.S. \& Kyotalimye M (ed), East African agriculture and climate change: a comprehensive analysis. International Food Policy Institute (IFPRI). 
Bauer, A., Feichtinger, J. \& Steurer, R. (2012), The Governance of Climate Change Adaptation in Ten Organization for Economic Co-operation and Development (OECD) Countries: Challenges and Approaches. Journal of Environmental Policy \& Planning. 14:3, pp 279 304. DOI: 10.1080/1523908X.2012.707406

Carmin, J., Anguelovski, I. \& Roberts, D. (2012), Urban climate adaptation in the global south: Planning in an emerging policy domain. Journal of Planning and Education Research 32(1): 18-32.

Climate and Development Knowledge Network (CDKN). (2014), The IPCC's Fifth Assessment Report: What's in it for Africa? CDKN.

Cobb, P., D’Souza, D., Switzer, J. \& Douglas, A. (2015), Role of policy in oil and gas adaptation: An analysis of policy drivers and barriers in the Alberta oil and gas sector. Climate Change Impacts and Adaptation Division, Natural Resources, Canada.

Cochrane, L., Cundill, G., Ludi, E., New, M., Nicholls, R.J., Wester, P., Cantin, B., Murali, K.S., Leone, M., Kituyi, E. \& Landry, M.E. (2017), A reflection on collaborative adaptation research in Africa and Asia. Reg. Environ Change 17(5): 1553-1561. DOI 10.1007/s10113-017-1140-6.

Connolly-Boutin, L. \& Smit, B. (2016), Climate change, food security and livelihoods in Sub-Saharan Africa. Regional Environmental Change 16(2): 385-399.

Development Initiatives. (2019), Tracking sub-national government investments in climate change mitigation and adaptation in Kenya: progress, challenges and opportunities. Report.

FAO. (2010), Climate smart agriculture: policies, practices and financing options for food security, adaptation and mitigation. The Hague Conference on agriculture, food security and climate change.

FAO. (2102), Smallholders and family farmers. Available at: http://www.fao.org/fileadmin/templates/nr/sustainability pathways/docs/Factsheet SMALLHOLDERS.pd. Accessed on $20^{\text {th }}$ January 2018.

FAO. (2017), The Impact of Disasters and Crises on Agriculture and Food Security. Rome, FAO.

Friis-Hansen, E., Bashaasha, B. \& Aben, C. (2013), Decentralization and implementation of climate change policy in Uganda. DIIS Working Paper 27.

Friis-Hansen, C. \& Aben, C. (2017), Local Politics of Climate Change Adaptation in Uganda. Book Chapter In: Friis-Hansen, E. (Ed.), Decentralized Governance of climate change adaptation in Africa. CAB International.

Government of Nepal, (2011), National Framework on Local Adaptation Plans for Action. Government of Nepal, Ministry of Environment, Singhdurbar.

Government of Uganda, (1997), The Local Governments Act 1997. Kampala, Uganda

Government of Uganda, (2007), Climate Change: Uganda National Adaptation Programmes of Action (NAPA). Ministry of Water and Environment, Kampala Uganda.

Government of Uganda, (2013), Integrated Territorial Climate Plan 2014 - 2029: for the Mable region of Uganda (Bududa, Manafwa and Mbale Districts). Kampala Uganda.

Government of Uganda, (2014a), Second National Communication to UNFCCC. Ministry of Water and Environment, Kampala Uganda.

Government of Uganda, (2014b), The Local Government Planning Guidelines. National Planning Authority. Kampala Uganda.

Government of Uganda, (2015a), National Climate Change Policy for Uganda. Ministry of Water and Environment, Kampala Uganda.

Government of Uganda, (2015b), Intended National Determined Contribution. Ministry of Water and Environment. Kampala Uganda.

Hisali, E., Birungi, P. \& Buyinza, F. (2011), Adaptation to climate change in Uganda: evidence from micro level data. Global Environ. Change, 21(4) 1245-1261.

Hoppe, T., Berg, M.M., van den Berg M., \& Coenen, F. (2014), Reflections on the uptake of climate change policies by local governments: facing the challenges of mitigation and adaptation. Energy, Sustainability and Society $4: 8$

International Centre for Integrated Mountain Development (ICIMOD). (2012), Role of Policy and Institutions in Local Adaptation to Climate Change. ICIMOD. Kathmandu, Nepal.

International Fund for Agricultural Development (IFAD). (2013), Adaptation for smallholder agriculture programme (ASAP). IFAD.

International Institute for Environment and Development (IIED). (2013), Climate change responses in Zimbabwe: local actions and national policy: Briefing. January 2013. Available at: http://pubs.iied.org/pdfs/17145IIED.pdf. Accessed on 22 February 2018.

IPCC, (2015), IPCC Expert Meeting on Climate Change, Food, and Agriculture. https://www.ipcc.ch/pdf/supporting-material/Food-EM MeetingReport FINAL.pdf. Accessed on 22 November 2017.

Jones, L, Carabine, E., Hickman, A., Langston, L., Moosa, S. \& Mukanya R. (2014), Exploring the role of climate science in supporting long-term adaptation and decision-making in sub Saharan Africa. Climate and 
Development knowledge Network (CDKN) working paper.

Jones, L., Dougill, A., Jones, R.G., Steynor, A., Watkiss, P., Kane, C., Koelle, B., Moufouma-Okia, W., Padgham, J., Ranger, N., Roux, J., Suarez, P., Tanner, T. \& Vincent, K. (2015), Ensuring climate information guides long-term development. Nat. Clim. Change 5: 812-814.

Kajumba, T. C., Karani, I., Fisher, S. (2016), A bottom-up approach: identifying national standard climate change indicators for Uganda. Country Report. IIED.

Kampala Capital City Authority (KCCA). (2016), Kampala Climate Change Action, Kampala Uganda.

Kissinger, G., Lee, D., Orindi, V.A., Narasimhan, P., King'uyu, S.M. \& Sova, C. (2013), Planning climate adaptation in agriculture: meta-synthesis of national adaptation plans in West and East Africa and South Asia. CCAFS Report No. 10. In: CGIAR Research Program on Climate Change, Agriculture and Food Security (CCAFS). Copenhagen, Denmark.

Lacey, A \& Luff, D. (2001), Trent focus for research and development in primary health care: An Introduction to qualitative analysis. Trent Focus.

Liwenga, E.T., Jalloh, A. \& Mogaka, H. (2014), Review of research and policies for climate change adaptation in the agriculture sector in East Africa. Future Agricultures; Working Paper No.103.

Lobell, D., Schlenker, W. \& Costa-Roberts, J. (2011), Climate trends and global crop production since 1980. Science 333 (6042): 616-620.

Luwero District Local Government. (2010), Five-year district development plan 2010/2011 - 2014/2015. Luwero District, Uganda.

Luque, A, Edwards G, A., Lalande, C. (2013), The local governance of climate change: new tools to respond to old limitations in Esmeraldas, Ecuador. Local Environment 18(6): 738-751.

Madzwamuse, M. (2010), Climate governance in Africa: Adaptation strategies and institutions. Available at: https://www.boell.de/en/ecology/africa-climate-governance-in-africa-adaptation-strategies-and-institutions10914.html. Accessed on 15 June 2017.

Mbale District Local Government. (2010), Five-year district development plan 2010/2011 - 2014/2015. Mbale District, Uganda.

Ministry of Water and Environment. (2015), Economic Assessment of the impacts of climate change in Uganda. Final Report. Ministry of Water and Environment, Kampala Uganda.

Morton J.F. (2007), The impact of climate change on smallholder and subsistence agriculture. Proceedings of the National academy of Sciences (PNAS) 104(50): 19680-19685.

Mubiru, D.N., Komutunga, E. \& Apok, A. (2010), Climate change and adaptation strategies in the Karamoja subregion. Survey report. DCA, Kampala, Uganda; 2010.

Mugumya, F. (2013), Enabling community-based water management systems: governance and sustainability of rural point-water facilities in Uganda. Doctoral dissertation, Dublin City University.

Mulinde, C, Majaliwa, J.G.M., Twinomuhangi, R., Mfitumukiza, D., Komutunga, E., Ampaire, E., Asiimwe, J., Van Asten, P. \& Jassogne, L. 2019, Perceived climate risks and adaptation drivers in diverse coffee landscapes of Uganda. NJAS - Wageningen Journal of Life Sciences 88: 31-44. https://doi.org/10.1016/j.njas.2018.12.002.

Nyasimi, M., Radeny, M., Mungai, C. \& Kamini, C. (2016), Uganda's national adaptation programme of action: implementation, challenges and emerging lessons. CGIAR Research Program on Climate Change, Agriculture and Food Security.

Okiror, J,J., Friis-Hansen, E., Bashaasha, B. \& Nakendo, I. (2017), A White Elephant in a Changing Climate: a Territorial Approach to Climate Change Adaptation in Uganda. Book Chapter In: Friis-Hansen E (Ed.) Decentralized Governance of climate change adaptation in Africa. CAB International.

Olazabal, M., Galarraga, I., Ford, J., De Murieta, E.S. \& Lesnikowski, A. (2019), Are local climate adaptation policies credible? A conceptual and operational assessment framework, International Journal of Urban Sustainable Development. DOI:10.1080/19463138.2019.1583234.

Pohlamann, A. (2011), Local climate change governance. Book Chapter In: Engels A (ed) Global transformations towards a low carbon society. Working Paper Series No.5, Hamburg: University of Hamburg.

Peniston, B. (2013), A Review of Nepal's Local Adaptation Plans of Action (LAPA). High Mountains Adaptation Partnership.

Preston, B.L., Rickards, L., Fünfgeld, H. \& Keenan, R.J. 2015. Toward reflexive climate adaptation research. Curr Opin Environ Sustain. 14:127-135.

Satterthwaite, D. (2011), How urban societies can adapt to resource shortage and climate change. Phil. Trans. R. Soc. A 369: 1762-1783. DOI:10.1098/rsta.2010.0350.

Spencer, L., Ritchie, J. \& O’Connor, W. (2003), Analysis: practices, principles and processes. Chapter In: Dans JR, Lewis L (ed), Qualitative research practice: A guide for social science students and researchers, p. 199218.

Tenywa, J.S., Nabasirye, M., Twinomuhangi, R., Mfitumukiza, D. (2017), Uptake of Knowledge and Technologies 
for Adaptation to Climate Change in Crop Production Systems in Uganda: A Review. Advances in Research 11(2): 1-14.

Tumushabe, G., Muyomba, L.T., Ssemakula, E. \& Lukwago, D. (2010), Uganda Local Government Councils Score-card Report 2008/2009: A Comparative Analysis of Findings and Recommendations for Action. Policy Research Series 35. Advocates Coalition for Development and Environment (ACODE).

Tumushabe, G., Muhumuza, T., Natamba, E., Neil, B., Welham, B. \& Jones, L. (2013), Uganda national climate change finance analysis: Report. Overseas Development Institute (ODI) and ACODE.

UNDP. (2013). Climate profiles and climate change vulnerability of the Mbale region of Uganda: Policy Brief. The TACC Mbale Project, Uganda.

UBOS. (2017), Uganda National Household Survey 2016/2017. UBOS. Kampala Uganda.

United Nations (2015). Paris Agreement. UNFCCC. Available at: https://unfccc.int/files/essential_background/convention/application/pdf/english_paris_agreement.pdf. Accessed on 22 July 2017.

USAID, (2013). Uganda Climate Change Vulnerability Assessment. USAID, African and Latin American Resilience to Climate Change (ARCC).

Winthrop, M., Kajumba, T.C. \& Maclvor, S. (2018). Uganda Country climate risk assessment report. Irish Aid, Resilience and Economic Inclusion Team, Policy Unit.

World Bank, (2012). Uganda Country Environmental Analysis: Final Report.

World Bank Group, (2015). Uganda: strategic climate diagnostic. World Bank Group.

Wright, H., Vermeulen, S., Lagand, G., Olupot, M., Ampaire, E. \& Jat, M.L. (2014), Farmers, food and finance: ensuring that community-based adaptation is mainstreamed into agricultural programmes. Clim. Dev 6(4): 318-328. 